\title{
Fault ergodicity algorithm for reliability evaluation of distribution system
}

\author{
Xu Xiufeng ${ }^{1, ~ a, ~ L a i ~ X u e b i n g ~}{ }^{2, b}$, Lu Junjie ${ }^{3, c}$ \\ ${ }^{1}$ Guangxi Power grid Pingxiang Power Supply Bureau, CHINA \\ ${ }^{2}$ Fangchenggang JINDA Electric Power Survey and Design Co., Ltd, CHINA \\ ${ }^{3}$ Guangxi Power grid Pingxiang Power Supply Bureau, CHINA \\ a4992690@163.com, b62111001@qq.com, ahjun291@163.com
}

\begin{abstract}
Keywords: Distribution network,reliability evaluation,fault algorithm,depth-first search,breadth-first search.

Abstract. A practical and fast fault ergodicity algorithm for the reliability evaluation of distribution system is proposed on the basis of a large number of analysis of the distribution network structure. The algorithm uses breadth first search and depth first search and the minimum path set for the load point to the power point in the graph theory, respectively to determine the fault of circuit breaker or fuse isolating switch action and fault isolation scope and load point fault type, the reliability index of the system is calculated according to the type of the fault of the load point. The calculation example shows that the algorithm can effectively implement the reliability evaluation of the complex distribution system, and it is a more practical algorithm for reliability evaluation.
\end{abstract}

\section{Preface}

As a subsystem of the whole power system in direct contact with the end users in distribution system is an important part of the system's safety and economic operation, once the distribution system failure or maintenance, users of the system will inevitably lead to power outages, and the distribution system with radio network structure, is sensitive to the fault, the outage fault mostly caused by the fault in the power distribution system. At the same time, due to the current user requirement of power supply reliability of distribution system more and more high, the reliability of distribution systems has become an important part of the study of the reliability of power system, which has attracted many domestic and foreign experts attention.

Domestic and foreign scholars have put forward various algorithms in the research of distribution system reliability, including Monte Carlo sampling method [1], network reliability equivalence method [2], network planning method [9] and so on. However, with the increasing power system and the complexity of distribution network structure, the modeling and calculation of its reliability have become more difficult. Therefore, how to balance between the accuracy and the amount of calculation and how to find fast and effective methods are all problems to be explored further. In view of this, this paper chooses fault traversal network topology algorithm, using the breadth search algorithm, depth search algorithm and the minimal path set of each load point to the power point, and combining the results of the distribution network power flow distribution, to achieve the reliability evaluation of distribution network.

\section{Reliability index of distribution system}

The reliability of distribution system (distribution system reliability) refers to the supply point to the user, including the measurement of substation, high and low voltage lines and grounding wire, the whole distribution system and equipment according to the accepted standard and the expected number of power and power quality to meet user demand ability.

In this paper, the reliability of the whole distribution system is characterized by two kinds of indexes, the reliability index of load point and the reliability of the system. 


\section{Reliability index of load point}

The reliability index of load point includes: load point fault rate, $\lambda$ (unit: times/a), average power outage duration for each fault of load point , $\mathrm{r}$ (unit: $\mathrm{H}$ times) and load point average annual outage time $U$ (unit: $h / a$ ) for $n$ series repairable components, the following formula can be used for this calculation:

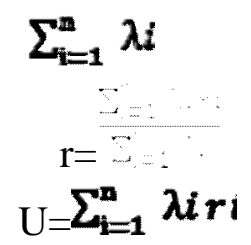

For two parallel repairable components, the following formula is used to calculate:

\section{$\lambda=\lambda 1 \lambda 2(r 1+r 2)$}

$$
\begin{aligned}
& \mathrm{r}= \\
& \mathrm{U}=\boldsymbol{\lambda}_{\mathrm{r}}
\end{aligned}
$$

\section{System reliability index}

System reliability index Includes: System Average interruption frequen-tcy index(System Average interruption frequen-tcy index, SAIFI),system average interruption duration index(System average interruption duration index, SAIDI) and average service availability index(Average service availability index, ASAI), expected energy not served (Expected energy not served, EENS). The formulae for each index are as follows:

\section{SALTI $=$}

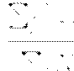

(times household·year)

Among them: Ni is the number of users of load point $\mathrm{i}$; $\mathrm{A}$ is the failure rate of the load point $\mathrm{i}$.

$$
\text { SAIDI }=\quad \frac{\Sigma_{l} N i U_{i}}{\Sigma_{\boldsymbol{T}} N i}
$$$$
\text { (hours/household·year) }
$$

Among them, $\mathrm{Ui}$ is the average annual fault time of the load point $\mathrm{i}$.

$$
\text { ASAI }=
$$

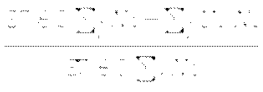

\section{Principle analysis}

Based on the idea of enumerating fault, this algorithm develops a reliability evaluation method by using ergodicity technology of DFS and BFS. Through the establishment of analysis list of effect of fault mode, it identifies each enumeration fault event and its influence ,it takes the power flow calculation of distribution network as the check basis, to determine the fault types of all load points caused by various kinds of fault enumeration, and then make a comprehensive analysis to calculate reliability index,therefore,this paper firstly classifies the load point of the network, makes a comprehensive analysis on this basis, so as to calculate the required reliability assessment index.

\section{Classification of fault types of load points}

Any failure event (this paper mainly considers components failures of lines, transformers, circuit breakers, disconnecting switches and combinatorial components failures ), and divides the load points into 4 categories according to the duration of power outage:

Class 1: power failure duration is component repair time;

Class II: the correct action of the switch after the occurrence of the fault is not affected by the fault.

Class III: power outage duration is isolated operation time; 
Class IV V: power outage duration is isolated operation time and switching operation time.

\section{The minimum path set of the load point}

For each branch of the system, all the anterior branch of the system can be obtained by the structure chain list of the system respectively. Therefore, the shortest path from the power point to the load point can be obtained by the recursive algorithm. First, we build a stack to stack the load point branch and traverse the previous branch. If the branch doesn't have a forward branch or a branch leads to a path cycle, the path is deleted. Otherwise, the branch stack will traverse the other preceding branches. If we traverse the output branch, we will terminate the calendar. Then, the branch that is stored in the stack is the shortest path. The shortest path set of the load point is formed by traversing each load branch.

\section{Determination of the type of load point fault}

According to the classification standard of the load point proposed in this paper, the following methods are used to determine the types of each load point in the actual system.

Determination of class I load point

When a component in the network fails, the breadth first search (BFS) sequence is used to search the parent node backwards until the first time there is a circuit breaker, fuse or disconnector. Circuit breaker, fuse or vibration isolation switch to remove the debt branch line to search, changing the topology of distribution network, and then from the source node start depth first search (DFS) traversal of the distribution network, so that those who do not have to traverse the load node is class load node, namely the node outage duration of repair the repair time for a component.

Determination of class II load point

When a fault occurs on a component in the network, by taking the branch of the component as the starting node, then it backward searches the parent node by using the order of breadth first search (BFS), until the first time occuring of the breakers and fuses, is the feeder for the circuit breaker or fuse branch is removed, the topological changes of distribution the grid, then from the source node start depth first search traversal (DFS) distribution network, you can traverse to the load node is class III load node, node failure that occurred after the correct switch action and not affected by the failure of the.

Determination of class III and V load points

The circuit breaker, fuse and isolator are determined by searching for the range of the fault and the influence scope of the component fault. It lays the foundation for the next step to determine the load nodes of class $\mathrm{V}$ and class IV. In addition to the above identified 1, I load, the remaining load node is, NV load node, they can be determined by the following methods: the grid topology on the component fault range traverse, those directly connected with the power supply load node (not by contact switch or contact knife smell) is class II the rest of the load node, left is IV V load node.

\section{Flow calculation in Power distribution}

The load change caused by the fault outage in the distribution system must be considered. Under the condition of neglecting line capacitance and load and reactive power, DC power flow method and $\mathrm{Z}$ matrix method can be used to solve the distribution of power flow in distribution network under line fault or load point load reduction.

\section{The Process of Algorithm Implementation}

Read the original data, through the adjacency list stored, dynamic representation of topological structure of distribution network, the formation of system topology information; 2. depth search (DFS), the formation of the load path set; fault enumeration 3. events; 4. with a breadth first traversal 
search method (BFS) to determine the scope of the fault and determine the fault the action of breakers and fuses: 5. using breadth first search method (BFS) is to determine the fault influence, determine the fault circuit breaker, fuse action and vibration isolation knife 6 . according to the fault distribution network topology structure, calculate the power flow distribution, the implementation of system fault recovery, system reconstruction, the formation of the subsystem; 7. by depth first search algorithm (DFS) traversal of each subsystem, identify load fault types; 8. according to the network load point fault types and load of reliability index calculation; check whether the 9. failure events after enumeration If completed, unfinished, go to step 3; 10. calculation results output, provide reference for system operation, management and planning departments and users.

To sum up, the flowchart of the program implementation is shown in Figure 1:

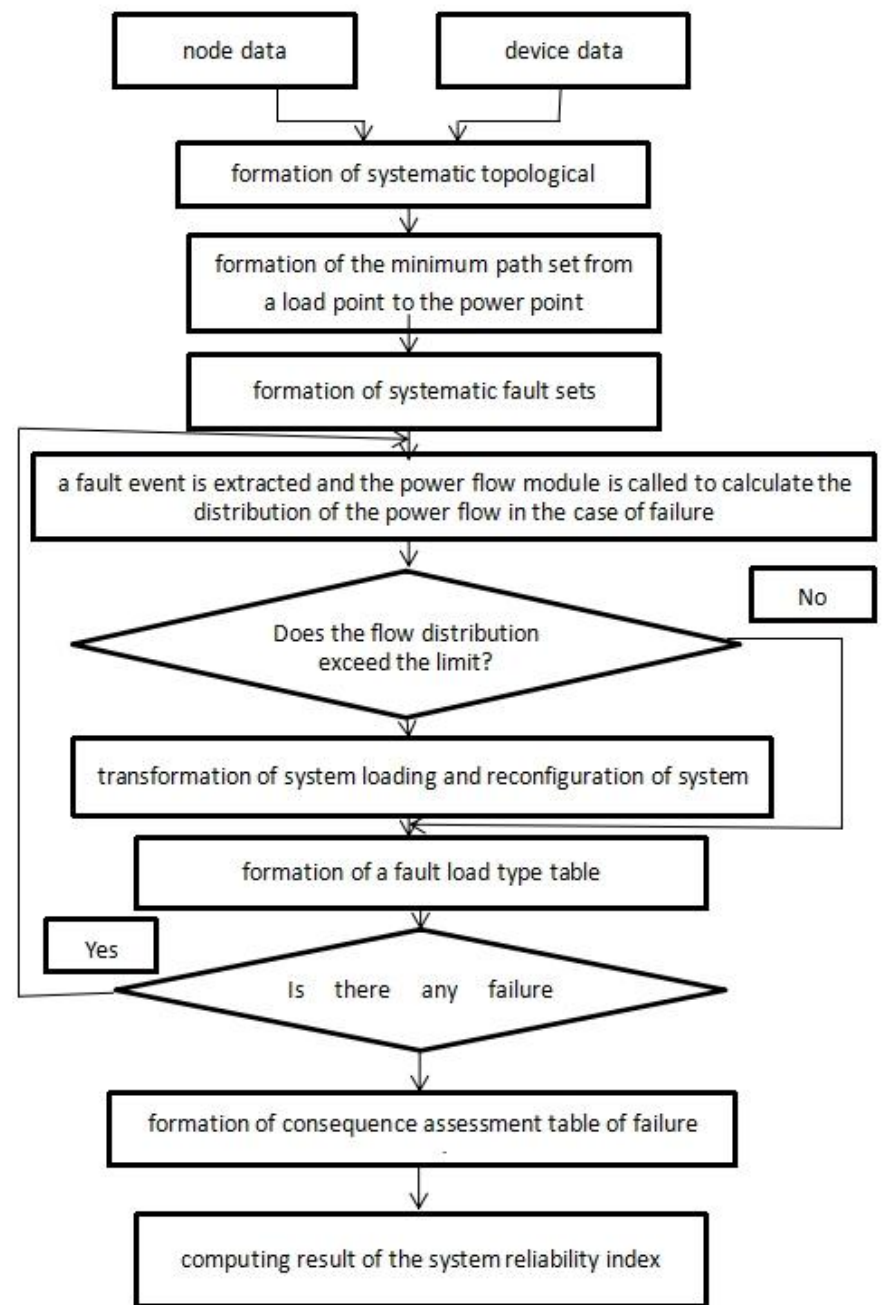

Figure 1 Program flow chart of distribution network reliability evaluation

\section{Test example}




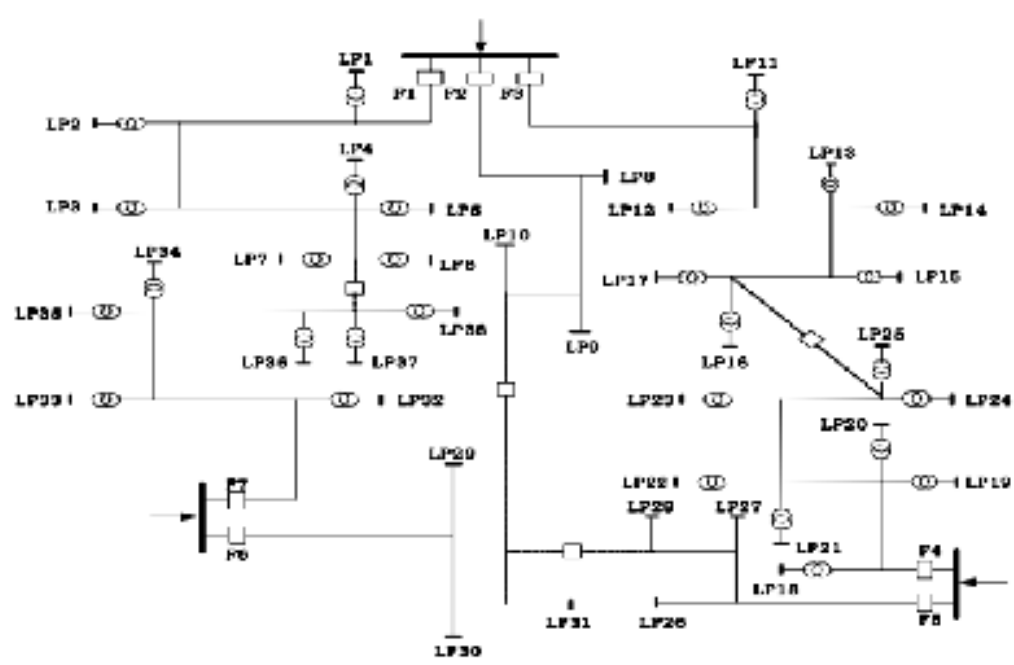

Figure 2 wiring diagram of $10 \mathrm{kV}$ distribution system in a certain planning area

This paper uses the $10 \mathrm{kV}$ distribution system of a planning area as a test example, the connection is as shown in Figure 2: the system has 7 main feeder lines (F1, F2, F3, F4, F5, F6, F7), F1 as one of main feeder lines, comes with 7 load points, F2 comes with 3 the load point, F3 comes with 7 load points, F4 comes with 8 load points, F5 with 3 load points, F6 comes with 3 load points,F7 comes with 5 load points. The reliability parameters of each component, the reliability index of the system and the cost of investment are shown in the following tables:

Table 1 User data

\begin{tabular}{llll}
\hline Load point number & Load point $(\mathrm{M} / \mathrm{W})$ & Load & Users \\
\hline 15 & $1-4,11-13,18-21,32-35$ & 0.8869 & 220 \\
7 & $5,14,15,22,23,36,37$ & 0.81378 & 200 \\
7 & $8,10,26-30$ & 1.6300 & 1 \\
2 & 9,31 & 2.445 & 1 \\
7 & $6,7,16,17,24,25,38$ & 0.6714 & 10 \\
Total & & 40 & 4779
\end{tabular}

Table 2 Component data

\begin{tabular}{llll}
\hline Componet & $\lambda / \mathrm{a}^{-1}$ & $\mathrm{R} / \mathrm{h}$ & Unit price(Dollars) \\
\hline Transformer 10/0.4 & 0.015 & 120 & 52,857 \\
Circuit breaker 10 & 0.006 & 2 & 4,286 \\
Fuse 10 & 0.013 & 0.3 & 286 \\
Force sluice 10 & 0.010 & 1.5 & 857 \\
Lines 10kV electric cable & 0.004 & 8 & 114,286 \\
\hline
\end{tabular}

Table 3 Feeder lines data

\begin{tabular}{lll}
\hline Feeder lines type & $\mathrm{L} / \mathrm{km}$ & Feeder lines number \\
\hline 1 & 0.60 & $2,6,10,14,17,21,25,28,30,34,38,41,43,46,49,51,55,58,61,64,67$ \\
2 & 0.75 & $35,37,40,42,45,48,52,53,56,60,63,65$ \\
3 & 0.80 & $36,39,44,47,52,54,57,59,62,66$ \\
\hline
\end{tabular}

Table 4 System reliability and cost investment results 


\begin{tabular}{|c|c|c|c|c|c|}
\hline Type & $\begin{array}{l}\text { System } \\
\text { Average } \\
\text { interruption } \\
\text { frequen-tcy } \\
\text { index } \\
(\mathrm{SAIFI}) / \mathrm{a}^{-1}\end{array}$ & $\begin{array}{l}\text { System } \\
\text { average } \\
\text { interruption } \\
\text { duration } \\
\text { index(SAIDI)/ } \\
\mathrm{h}^{*} \mathrm{a}^{-1}\end{array}$ & $\begin{array}{l}\text { Average } \\
\text { service } \\
\text { availability } \\
\text { index } \\
\text { (ASAI) }\end{array}$ & $\begin{array}{l}\text { Expecte } \\
\text { d energy } \\
\text { not } \\
\text { served( } \\
\text { EENS)/ } \\
\mathrm{MW}^{* \mathrm{H}} \\
*_{\mathrm{a}}{ }^{-1}\end{array}$ & $\begin{array}{l}\text { Investment } \\
\text { cost of power } \\
\text { grid(Dollars) }\end{array}$ \\
\hline I & 0.469786 & 15.9402 & 0.99818 & 443.507 & $1,883,143$ \\
\hline II & 0.297286 & 3.44871 & 0.999606 & 138.253 & $1,894,000$ \\
\hline III & 0.347669 & 2.65629 & 0.999697 & 113.609 & $1,916,857$ \\
\hline IV & 0.109939 & 2.48948 & 0.999716 & 108.638 & $2,006,000$ \\
\hline
\end{tabular}

The fault isolation time for the system is taken for 0.5 hours, and the power supply time of the load is 0.7 hours. The reliability and cost analysis of the system are divided into 4 types:

Class I: calculated according to the wiring diagram of the distribution system in Figure 1.

Class II: adding a fuse in the load branch of Figure 1;

Class III: adding a fuse in the load branch of Figure 1, and a contact knife switch in the main feeder lines branch.

Class IV: Adding a fuse in the load branch of Figure 1, and a connection switch in the branch of main feeder lines.

As can be seen from table 4, as the system configuration changes, the system reliability index rises as well as the investment cost of the system. This phenomenon is reasonable and scientific. According to the average electricity price conversion multiple method, if the average electricity price is $0.35 \mathrm{RMB} \mathrm{kW} / \mathrm{h}$ and the conversion ratio is 25 , taking class I as the comparison standard, then the relationship of the annual power outage loss and the additional investment for improving the reliability level is shown in Table 5.

Table 5 Results of systematic economic investment analysis

\begin{tabular}{lllll}
\hline Type & $\begin{array}{l}\text { Investment cost of } \\
\text { power grid(Dollars) }\end{array}$ & $\begin{array}{l}\text { Annual Power } \\
\text { outage loss of the } \\
\text { system(Dollars) }\end{array}$ & $\begin{array}{l}\text { Increase the } \\
\text { reliability of } \\
\text { additional } \\
\text { investment(Dollars) }\end{array}$ & $\begin{array}{l}\text { Power outage loss } \\
\text { plus additional } \\
\text { investment(Dollars) }\end{array}$ \\
\hline I & $1,883,143$ & 554,384 & 0 & 554,384 \\
II & $1,894,000$ & 172,816 & 10,857 & 183,672 \\
III & $1,916,857$ & 142,011 & 33,714 & 175,726 \\
IV & $2,006,000$ & 135,797 & 122,857 & 258,654 \\
\hline
\end{tabular}

As can be seen from table 5, according to the power outage loss and the minimum investment cost added by the system to increase the reliability level, the third option in the four investment plans is the best investment plan.

\section{Conclusion}

Through the discussion above, we can draw the following conclusions:

1.The method proposed in this paper is calculated by an example. The results show that the method is feasible, and the correctness of the model is verified.

2.The assessment takes into account the actual conditions of the distribution system, such as sub branch protection, isolation switch, the configuration of the segmented circuit breaker and the influence of the standby power supply.

3.According to the principle of power outage loss and the minimum investment cost for increasing the reliability level, by comparing the different schemes, this article gives the best investment strategy. The engineering verification is feasible, reasonable and scientific.

4.The reliability level of the distribution system is closely related to the wiring mode of the distribution system. In the case of permitting of economic conditions, a circuit breaker, a fuse, a load 
switch or, isolation switch and other sectionings can be set up to improve the reliability of the distribution system. Since this method increases investment, the coordination of economy and reliability should be considered in practical application.

5.The reliability of equipment componentS directly affects the overall reliability level of the system. The reliability index of the system can be improved effectively by reducing the failure rate and the fault time.

\section{References}

[1] Bilinton R, Wang P. Teachng distrbution system reliability evalation using monte-carlo simulation[J]. IEEE Transion power systems 1999,14(2): 309-403.

[2] Billinton R, Wang P. Reliability -network equivalent approach to distrbution system reliability evalation[J]. IEEE Proceeding generation transmission distrbution, 1998,14(2): 149-153.

[3] Billinton R, Billinton J E. Distrbution system reliability indices[J]. IEEE Transion power systems 1989,4(1):561-568.

[4] Billinton R, Allanr N. Reliability evaltion of power systems[M]. London: Pitman advanced Publishing program.(1984)

[5] Allan R N, Billinton R. Areliability test system for educational purposes basic distrbution system data and results[J]. IEEE Transion power systems 1991, 6(2): 813-821.

[6] Chem Lin Chen, Jann Liang Chess A neural network approach for evalation distribution system reliability[J]. Electric power systems research, 1993,(26): 225-229. 